\title{
FAKTOR-FAKTOR YANG MEMENGARUHI PROFITABILITAS BANK UMUM SYARIAH DI INDONESIA
}

\author{
Eliza Christabella Phuanerys \\ Program Studi Magister Manajemen Universitas Tarumanagara \\ elizachristabel@gmail.com \\ Yanuar \\ Program Studi Magister Manajemen Universitas Tarumanagara
}

Masuk : 14-11-2019, revisi : 29-11-2019 diterima untuk diterbitkan : 30-11-2019

\begin{abstract}
This study was conducted to analyze the effect of the Capital Adequacy, Asset Quality, Management Efficiency and Liquidity Management ratios on profitability proxied by bank Return On Assets (ROA), by analyzing the annual financial statements that have been published in 2013-2017. The variables used in analyzing the financial statements of Sharia Commercial Banks that are sampled are Asset Quality which is proxied by Non Performing Financing (NPF), Liquidity Management which is proxied by Financing to Debt Ratio (FDR), Management Efficiency proxied by Net Operating Margin (NOM), and Capital Adequacy proxied by Capital Adequacy Ratio (CAR). The sample in this study was 11 Islamic commercial banks for 5 years, namely 2013-2017. The results showed that Capital Adequacy, Asset Quality, and Liquidity Management significantly influenced the profitability of Islamic commercial banks. Whereas Management Efficiency does not affect the profitability of Islamic commercial banks. Based on these results, Sharia Commercial Banks in Indonesia must increase capital, reduce problematic financing by improving internal processes, and increase bank liquidity by increasing fundraising.
\end{abstract}

Abstrak : Penelitian ini dilakukan untuk menganalisis pengaruh rasio Capital Adequacy, Asset Quality, Management Efficiency dan Liquidity Management terhadap profitabilitas yang diproksikan dengan Return On Asset (ROA) bank, dengan menganalisa laporan keuangan tahunan yang telah dipublikasikan periode 2013-2017. Variabel yang digunakan dalam menganalisis laporan keuangan dari Bank Umum Syariah yang menjadi sampel adalah Asset Quality yang diproksikan dengan Non Performing Financing (NPF), Liquidity Management yang diproksikan dengan Financing to Debt Ratio (FDR), Management Efficiency yang diproksikan dengan Net Operating Margin (NOM), dan Capital Adequacy yang diproksikan dengan Capital Adequacy Ratio (CAR). Sampel dalam penelitian ini adalah 11 bank umum syariah selama 5 tahun yaitu tahun 2013-2017. Hasil penelitian menunjukkan bahwa Capital Adequacy, Asset Quality, dan Liquidity Management berpengaruh signifikan terhadap profitabilitas bank umum syariah. Sedangkan Management Efficiency tidak berpengaruh terhadap profitabilitas bank umum syariah. Berdasarkan hasil penelitian tersebut, Bank Umum Syariah di Indonesia harus meningkatkan permodalan, menurunkan pembiayaan bermasalah dengan memperbaiki proses internalnya, dan meningkatkan likuiditas bank dengan meningkatkan penghimpunan dana.

Keywords : CAR, NOM, FDR, NPF, ROA, Profitabilitas, Bank Umum Syariah

\section{PENDAHULUAN}

Beberapa penelitian terdahulu menemukan bahwa Bank Umum Syariah menunjukkan profitabilitas yang lebih tinggi daripada bank umum konvensional, penelitian (Kakakhel, Raheem, \& Tariq, 2016) di Pakistan, (Khediri, Charfeddine, \& Youssef, 2015) di negara- 
negara Gulf Cooperation Council, (Ramlan \& Adnan, 2016) di Malaysia, (Erol, Baklaci, Aydoğan, \& Tunç, 2014) di Turki dan (Ibrahim, 2015) di United Arab Emirates menemukan bahwa bank syariah memiliki tingkat profitabilitas yang lebih tinggi daripada bank konvensional.

Temuan hasil penelitian diatas didukung oleh kutipan berita (Rossiana, G., 27 Februari 2018) Laba bersih perbankan syariah hingga akhir 2017 mencapai Rp 3,08 triliun. Nilai tersebut melonjak 47,36\% dibandingkan perolehan pada akhir 2016 yang mencapai Rp 2,09 triliun. Dalam Laporan Tahunan Bank Maybank Syariah tahun 2017 disebutkan bahwa pertumbuhan perbankan syariah mampu mengimbangi bahkan melampaui perbankan konvensional, meskipun total pangsa pasar aset perbankan syariah hanya 5,73\% dari bank konvensional.

Merujuk pada temuan dan hasil penelitian diatas, peneliti tertarik untuk mengetahui faktor-faktor apa saja yang memengaruhi profitabilitas Bank Umum Syariah di Indonesia periode 2013-2017.

\section{TINJAUAN LITERATUR Profitabilitas}

Variabel Profitabilitas yang diproksikan dengan Return On Asset (ROA). Return On Assets (ROA) merupakan rasio untuk mengukur kemampuan perusahaan dalam mendayagunakan aset untuk memperoleh laba (Prihadi, 2013).

\section{Capital Adequacy}

Capital Adequacy yang diproksikan dengan Capital Adequacy Ratio (CAR) adalah rasio yang digunakan untuk mengukur kecukupan modal yang dimiliki bank yang mengandung atau menghasilkan risiko, misalnya kredit atau pembiayaan yang diberikan.

\section{Asset Quality}

Asset Quality yang diproksikan dengan Non Performing Financing merupakan risiko akibat kegagalan debitur atau pihak lain dalam memenuhi kewajiban kepada bank. Risiko kredit umumnya terdapat pada seluruh aktivitas bank yang kinerjanya bergantung pada kinerja pihak lawan (counterparty), penerbit (issuer), atau kinerja penyedia dana (borrower). Risiko kredit dapat meningkat antara lain karena terkonsentrasinya penyediaan dana pada debitur, wilayah geografis, produk, jenis pembiayaan, atau lapangan usaha tertentu (bi.go.id). Posisi NPF yang dipersyaratkan Bank Indonesia yaitu dibawah 5\%. Semakin tinggi NPF maka kinerja perbankan akan menurun.

\section{Liquidity Management}

Liquidity Management yang diproksikan dengan Financing to Deposit Ratio adalah risiko akibat ketidakmampuan bank untuk memenuhi kewajiban yang jatuh tempo dari sumber pendanaan arus kas dan/atau dari aset likuid yang dapat digunakan, tanpa mengganggu aktivitas dari kondisi keuangan bank. Risiko likuiditas disebut juga risiko likuiditas pendanaan (funding liquidity risk) dan risiko likuiditas pasar (market liquidity risk) (bi.go.id). rasio ini dirumuskan dengan menghitung rasio Financing to Debt Ratio (FDR).

\section{Management Efficiency}

Management Effficiency yang diproksikan dengan Net Operating Margin adalah rasio rentabilitas yang menunjukkan perbandingan antara pendapatan bunga bersih dengan rata-rata aktiva produktifnya yang dimiliki bank (Pandia, 2012). Rasio ini dihitung untuk mengukur keberhasilan manajemen dalam menghasilkan laba. Semakin kecil rasio ini berarti bank kurang mampu dalam mengelola asset untuk meningkatkan pendapatan dan menekan biaya. 


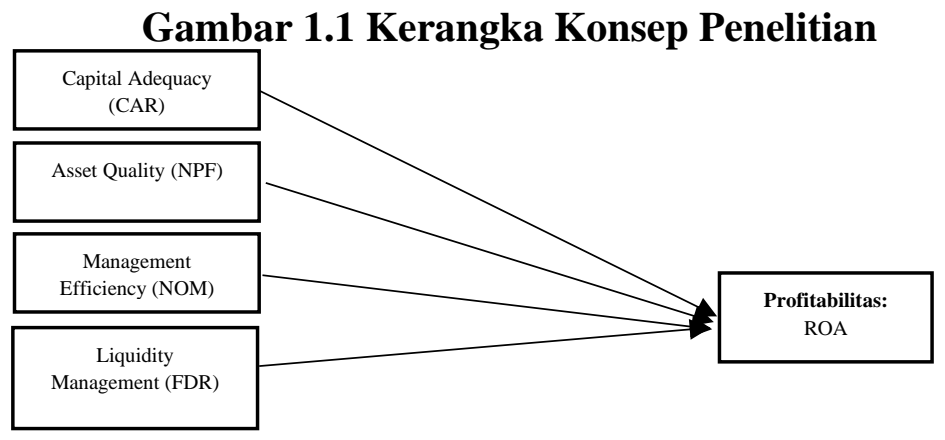

\section{Hipotesis}

H1: Capital Adequacy berpengaruh signifikan terhadap Profitabilitas

H2: Asset Quality berpengaruh signifikan terhadap Profitabilitas

H3: Management Efficiency berpengaruh signifikan terhadap Profitabilitas

H4: Liquidity Management berpengaruh signifikan terhadap Profitabilitas

\section{METODE PENELITIAN}

Jenis penelitian yang dilakukan adalah penelitian deskriptif kuantitatif. Rencana periode penelitian ini adalah tahun 2013-2017. Data yang digunakan dalam penelitian ini adalah data sekunder.

Populasi dalam penelitian ini adalah Bank Umum Syariah di Indonesia yang terdaftar di Bank Indonesia dan OJK. Sampel yang diambil yaitu 11 (sebelas) Bank Umum Syariah di Indonesia yang tercatat di Bank Indonesia dan OJK dan berdiri sejak minimal awal tahun penelitian yaitu tahun 2013 .

Tabel 1.1

\begin{tabular}{|l|}
\multicolumn{1}{|c|}{ Sampel Penelitian } \\
\hline PT Bank BNI Syariah \\
\hline PT Bank Mega Syariah \\
\hline PT Bank Muamalat Indonesia \\
\hline PT Bank Syariah Mandiri \\
\hline PT Bank BCA Syariah \\
\hline PT Bank BRI Syariah \\
\hline PT Bank JABAR Banten Syariah \\
\hline PT Bank Syariah Bukopin \\
\hline PT Bank Victoria Syariah \\
\hline PT Bank Maybank Syariah \\
\hline PT Bank Panin Dubai Syariah \\
\hline
\end{tabular}

Sumber: Direktori Perbankan Indonesia 2017. Indonesia Banking Directory 2017

Penelitian ini menggunakan teknik analisis model regresi linear berganda. Model regresi linear berganda ini digunakan untuk mengetahui bagaimana pengaruh Capital Adequacy yang diproksikan dengan Capital Adequacy Ratio (CAR), Assets Quality yang diproksikan dengan Non Performing Financing (NPL), Liquidity Management yang diproksikan dengan Financing to Deposits Ratio (FDR) dan Management Efficiency yang diproksikan dengan Net Operating Margin (NOM) terhadap Profitabilitas yang diproksikan dengan Return On Assets (ROA) pada Bank Umum Syariah dengan aplikasi pengolahan data Eviews 9. Menurut Widarjono (2007) model estimasi data panel dapat dilakukan melalui 3 pendekatan yaitu Common Effect Model, Fixed Effect Model dan Random Effect Model.

\section{HASIL PENELITIAN DAN PEMBAHASAN}

\section{Chow Test}

Pengujian Chow Test dilakukan untuk menentukan model Common Effect atau Fixed Effect yang lebih tepat digunakan. Hasil hipotesis yang dibentuk dalam Chow Test adalah 
apabila nilai probabilitas lebih besar dari tingkat signifikan $(>0.05)$, maka data tersebut adalah Common Effect Model, jika nilai probabilitas lebih kecil dari $0.05(<0.05)$, maka data tersebut adalah Fixed Effect Model. Jika hasil hipotesis adalah Fixed Effect Model, selanjutnya dilakukan pengujian Hausman Test.

\section{Tabel 1.3}

Redundant Fixed Effects Tests

Pool: POOL

Test cross-section fixed effects

\begin{tabular}{lrrr}
\hline \hline Effects Test & Statistic & d.f. & Prob. \\
\hline \hline Cross-section F & 3.044080 & $(10,40)$ & 0.0059 \\
Cross-section Chi-square & 31.124129 & 10 & 0.0006 \\
\hline \hline
\end{tabular}

Sumber: diolah peneliti (2019)

Berdasarkan hasil uji Chow Test, memperlihatkan nilai probabilitas lebih kecil dari 0.05 pada Cross Section Chi-Square, hal ini menunjukkan bahwa H0 ditolak maka data sampel merupakan Fixed Effect Model. Namun karena data merupakan Fixed Effect Model, peneliti melanjutkan pengujian hipotesis dengan uji Hausman Test.

\section{Uji Hausman Test}

Pengujian Hausman Test dilakukan untuk pengujian statistik dalam memilih dan menentukan Fixed Effect Model atau Random Effect Model yang lebih tepat digunakan. Hasil hipotesis yang dibentuk dalam Hausman Test adalah apabila nilai probabilitas lebih besar dari tingkat signifikan (>0.05) maka data tersebut adalah Random Effect Model. Jika nilai probabilitas lebih kecil dari tingkat signifikan $(<0.05)$, maka data tersebut adalah Fixed Effect Model. Jika hasil hipotesis adalah Fixed Effect Model, selanjutnya akan dilakukan Lagrange Multiplier Effect.

\section{Tabel 1.4}

Correlated Random Effects - Hausman Test

Pool: POOL

Test cross-section random effects

\begin{tabular}{|c|c|c|c|}
\hline Test Summary & Chi-Sq. Statistic & Chi-Sq. d.f. & Prob. \\
\hline Cross-section random & 26.931464 & 4 & 0.0000 \\
\hline R-squared & 0.795141 Mean depen & t var & 0.002182 \\
\hline Adjusted R-squared & 0.723440 S.D. depend & var & 3.781942 \\
\hline S.E. of regression & 1.988886 Akaike info & erion & 4.440027 \\
\hline Sum squared resid & 158.2266 Schwarz crit & & 4.987481 \\
\hline Log likelihood & -107.1007 Hannan-Qui & criter. & 4.651732 \\
\hline F-statistic & 11.08970 Durbin-Wats & stat & 2.574749 \\
\hline Prob(F-statistic) & 0.000000 & & \\
\hline
\end{tabular}

Sumber: diolah peneliti (2019)

Berdasarkan hasil uji Hausman Test, memperlihatkan nilai probabilitas sebesar 0.000 maka data sampel merupakan Fixed Effect Model. Nilai Adjusted R Square sebesar 0.795141 dan lebih besar dari 0.5 yang menunjukkan kemampuan variabel bebas kuat dalam menjelaskan keterbatasan variabel dependen. Maka tidak perlu melakukan pengujian Lagrange Multiplier Test.

\section{Uji F}

Uji $\mathrm{F}$ berguna untuk menunjukkan bahwa semua variabel independen dalam model memiliki pengaruh yang simultan terhadap variabel dependen (Ghozali, 2013). Penentuan hasil uji $\mathrm{F}$ adalah apabila nilai probabilitas di bawah $0.05(<0.05)$, artinya variabel bebas secara simultan berpengaruh terhadap variabel dependen. Apabila nilai probabilitas di atas 0.05 (> $0.05)$, artinya variabel bebas secara simultan tidak berpengaruh terhadap variabel dependen. 


\section{Tabel 1.5}

Hasil Uji F

\begin{tabular}{lll}
\hline R-squared & 0.795141 Mean dependent var & 0.002182 \\
Adjusted R-squared & 0.723440 S.D. dependent var & 3.781942 \\
S.E. of regression & 1.988886 Akaike info criterion & 4.440027 \\
Sum squared resid & 158.2266 Schwarz criterion & 4.987481 \\
Log likelihood & -107.1007 Hannan-Quinn criter. & 4.651732 \\
F-statistic & 11.08970 Durbin-Watson stat & 2.574749 \\
Prob(F-statistic) & 0.000000 & \\
\hline
\end{tabular}

Sumber: diolah peneliti (2019)

Berdasarkan tabel di atas, dapat dilihat bahwa Prob(F-statistic) sebesar 0.000000 lebih kecil dari 0.05 , sehingga dapat disimpulkan bahwa variabel independen secara simultan berpengaruh terhadap variabel dependen atau paling tidak ada salah satu peubah bebas yang berpengaruh signifikan terhadap profitabilitas.

\section{Uji t}

Menurut Ghozali (2013) uji statistik T digunakan untuk menunjukkan besarnya pengaruh satu variabel bebas terhadap variabel dependen dengan menganggap variabel bebas lainnya konstan. Penentuan hasil uji T adalah apabila nilai probabilitas dibawah $0.05(<0.05)$, artinya pengaruh variabel bebas signifikan terhadap variabel dependen. Apabila nilai probabilitas di atas 0.05 (> 0.05), artinya pengaruh variabel bebas tidak signifikan terhadap variabel dependen.

\section{Tabel 1.6}

Hasil Uji t

Dependent Variable: Profitabilitas?

Method: Panel Least Squares

Date: 05/06/19 Time: 19:17

Sample: 20132017

Included observations: 5

Cross-sections included: 11

Total pool (balanced) observations: 55

\begin{tabular}{crrrr}
\hline \hline Variable & Coefficient & Std. Error & t-Statistic & Prob. \\
\hline \hline C & -11.50259 & 3.403808 & -3.379329 & 0.0016 \\
CA? & 0.306408 & 0.068531 & 4.471094 & 0.0001 \\
ME? & -0.014222 & 0.059277 & -0.239930 & 0.8116 \\
LM? & 0.072888 & 0.029422 & 2.477305 & 0.0176 \\
AQ? & -0.335187 & 0.060159 & -5.571687 & 0.0000 \\
\hline \hline
\end{tabular}

Sumber: data diolah (2019)

Uji t menunjukkan nilai prob. Capital Adequacy sebesar 0.0001 lebih kecil dari 0.05, sehingga dapat disimpulkan bahwa Capital Adequacy berpengaruh signifikan terhadap Profitabilitas pada Bank Umum Syariah di Indonesia

Uji t juga menunjukkan nilai prob. Management Efficiency sebesar 0.8116 lebih besar dari 0.05 sehingga dapat disimpulkan bahwa Management Efficiency tidak berpengaruh signifikan terhadap Profitabilitas pada Bank Umum Syariah di Indonesia

Uji t pada hasil pengujian nilai prob Liquidity Management menunjukkan hasil sebesar 0.0176 lebih kecil dari 0.05, sehingga dapat disimpulkan bahwa Liquidity Management berpengaruh signifikan terhadap Profitabilitas pada Bank Umum Syariah di Indonesia

Berdasarkan uji t, nilai prob. Asset Quality menunjukkan hasil sebesar 0.0000 lebih kecil dari 0.05, sehingga dapat disimpulkan bahwa Asset Quality berpengaaruh signifikan terhadap Profitabilitas Bank Umum Syariah di Indonesia. 


\section{KESIMPULAN DAN IMPLIKASI}

Berdasarkan hasil penelitian ini, dapat disimpulkan bahwa profitabilitas bank umum syariah di Indonesia dipengaruhi oleh permodalan, likuiditas dan risiko pembiayaan. Sesuai dengan hasil statistik yang telah dilakukan. Maka diperoleh kesimpulan sebagai berikut:

1. Peningkatan kecukupan modal oleh bank umum syariah akan membuat bank semakin leluasa dan memiliki peluang yang cukup besar untuk melakukan ekspansi pembiayaan dengan lebih aman kedalam aktivitas investasi yang menguntungkan sehingga bank umum syariah diharapkan dapat mencukupi kebutuhan modal minimum sebesar 8\%-11\% dari Aset Tertimbang Menurut Risiko (ATMR) bagi Bank dengan profil risiko peringkat 1 - peringkat 5. (POJK No 11/POJK.03/2016)

2. NPF mencerminkan risiko pembiayaan, semakin tinggi rasio NPF menunjukkan kualitas pembiayaan bank syariah semakin buruk. Bank umum syariah diharapkan dapat menurunkan pembiayaan bermasalah dengan cara memperbaiki proses internalnya agar semakin hati-hati dalam menyalurkan pembiayaan

3. Pada bank umum syariah lebih dominan melakukan pembiayaan untuk konsumsi dan modal kerja. Pembiayaan terhadap pendanaan harus dijaga pada kisaran diatas $90 \%$. Hal ini bertujuan supaya bagi hasil kepada nasabah kompetitif.

4. Management Efficiency Bank Umum Syariah tidak dipengaruhi oleh kemampuan bank dalam mengelola aktiva produktifnya.

\section{DAFTAR PUSTAKA}

Pandia, Frianto. 2012. Manajemen Dana dan Kesehatan Bank. Rineka Cipta: Jakarta

Sugiyono. 2016. Metode Penelitian Manajemen. Alfabeta: Bandung.

Widarjono, Agus. 2017. Ekonometrika Pengantar dan Aplikasinya disertai Panduan Eviews. UPP STIM YKPN: Yogyakarta.

Erol, C., Baklaci, H. F., Aydoğan, B., \& Tunç, G. (2014). Performance comparison of islamic (participation)banks and commercial banks in Turkish banking sector. EuroMed Journal of Business, 9(2), 114-128. https://doi.org/10.1108/EMJB-05-2013-0024

Ibrahim, M. (2015). International Journal of Economics and Financial Issues A Comparative Study of Financial Performance between Conventional and Islamic Banking in United Arab Emirates. International Journal of Economics and Financial Issues, 5(4), 868-874. https://doi.org/10.3844/ajebasp.2015.106.111

Kakakhel, S. J., Raheem, F., \& Tariq, M. (2011). A Study of performance comparison between conventional and and Islamic banking in Pakistan. Abasyn Journal of Social Sciences, 6(2), 91-105. https://doi.org/10.1007/s13398-014-0173-7.2

Khediri, K. Ben, Charfeddine, L., \& Youssef, S. Ben. (2015). Islamic versus conventional banks in the GCC countries: A comparative study using classification techniques. Research in International Business and Finance, 33, 75-98. https://doi.org/10.1016/j.ribaf.2014.07.002

Ramlan, H., \& Adnan, M. S. (2016). The Profitability of Islamic and Conventional Bank: Case Study in Malaysia. Procedia Economics and Finance, 35(October 2015), 359-367. https://doi.org/10.1016/S2212-5671(16)00044-7

https://www.ojk.go.id/id/kanal/perbankan/regulasi/peraturan-ojk/Documents/Pages/pojk11kewajiban-penyediaan-modal-minimum-bank-umum/SALINAN-

POJK.11\%20Konversi\%20KPMM\%20FINALE.pdf

https://keuangan.kontan.co.id/news/ini-strategi-bri-syariah-untuk-jaga-likuiditas https://www.cnbcindonesia.com/syariah/20180227165732-29-5623/laba-bersih-perbankansyariah-naik-4736-di-2017 